\title{
High Frequency of Lumbar Fusion in Patients Denied Surgical Treatment of the Sacroiliac Joint
}

\section{Abstract}

Purpose. Effective treatment of medical conditions relies on proper diagnosis. Clinical trials show the safety and effectiveness of sacroiliac joint (SIJ) fusion in patients with chronic SI joint dysfunction. To what extent is the condition under recognised?

Objective. To determine whether under recognition of SIJ pain affects healthcare trajectories in Spanish patients with low back pain.

Methods. Retrospective study of characteristics and consequences of 189 patients with persistent SIJ pain seen in an outpatient neurosurgery clinic.

Results. Patients with SIJ pain who were denied surgical treatment had a longer pain duration, higher likelihood of prior lumbar fusion, and a high rate (63\%) of lumbar fusion within 2 years prior to SIJ pain diagnosis, which, in most cases, provided little benefit.

Conclusions. Lack of knowledge of the role of the SIJ in chronic low back pain probably results in diagnostic confusion and may lead to misdirected treatment.

Keywords: sacroiliac joint pain; low back pain; misdiagnosis; surgical treatment 


\section{Introduction}

Background and rationale. Pain from the sacroiliac joint (SIJ) was recognised in ancient Greece and autoimmune pain from the SIJ (e.g., in ankylosing spondylitis) is an active topic of basic research. SIJ pain resulting from osteoarthritic degeneration or trauma remains poorly recognised by the neurosurgical community, even though the earliest reported SIJ arthrodesis surgery (1908(1)) predates surgery on the lumbar spine (1934(2)).

$15-25 \%$ of patients with chronic low back pain have pain that involves the SIJ.(3,4) Patients with chronic SIJ pain have low quality of life (5) and chronic SIJ pain is associated with high healthcare costs. $(6,7)$

Many patients with acute SIJ pain respond to conservative treatments (e.g., rest, physiotherapy). Patients who do not respond to conservative treatments may be candidates for more invasive non-surgical treatments, such as intraarticular steroid injections and radiofrequency (RF) ablation of lateral branches of the sacral nerves. When non-surgical treatment fails, SIJ fusion may be a valid option. High-quality evidence for long-term responses from SIJ steroid injections and RF ablation is lacking. In contrast, two surgery vs. non-surgery prospective randomized controlled trials have shown that minimally invasive SIJ fusion using triangular titanium implants resulted in superior pain, disability and quality of life outcomes compared to non-surgical treatment, along with a reduction in opioid use. $(8,9)$

Our previously reported 6-year experience with surgical and non-surgical treatments of chronic SIJ pain confirmed that patients undergoing SIJ fusion obtained immediate, sustained and clinically important improvements in pain and disability, improved work status and decreased opioid use compared with no pain/disability improvement, worsened work status and increased opioid use in patients who 
underwent non-surgical treatments.(10) In our experience with this cohort, we observed patterns of healthcare use and insurance coverage that suggest a high rate of misdiagnosis. Herein describe baseline and diagnostic characteristics of patients with SI joint pain, focusing on surgeries received prior to diagnosis.

\section{Materials and Methods}

Setting and participants. Between January 2007 and September 2017, >475 adult patients were evaluated in our neurosurgical department for chronic low back pain.(10) We diagnosed probable SIJ pain using the following criteria: 3 or more months of pain in the lumbosacral area immediately medial and below the posterior superior iliac spine with possible radiation into the buttocks, posterior thigh or groin (minimum pain score of 5 on the $0-10$ visual analogue scale [VAS]) with no focal neurological signs, an Oswestry Disability Index (ODI) score of at least 30\%, a positive Fortin finger test(11) and positive findings on at least 3 of 5 physical examination manoeuvres that stress the SIJ (FABER test, Patrick's test, thigh thrust, distraction test, compression test, Gaenslen test, sacral thrust and Yeoman test). Having 3 or more positive physical examination findings has high predictive power for a positive SIJ block, a reference standard for the diagnosis of SIJ pain.(12)

Patients with low back pain were typically provided conservative treatments only, including counselling for smoking cessation and weight control, physiotherapist consultation regarding chronic pain behaviour avoidance, and use of non-steroidal antiinflammatory agents. Patients whose pain persisted at 6 months underwent a confirmatory diagnostic SIJ block using intraarticular contrast and local anaesthetic (bupivacaine 1.5ml). Confirmed SIJ pain was diagnosed if, along with historical and physical examination findings, contrast was observed on fluoroscopy inside the SIJ and the patient reported acute pain relief of $50 \%$ or more. (Our criteria for SIJ pain 
diagnosis are like those used in standard clinical practice and in prospective clinical trials.) The analysis reported herein focuses on SIJ pain related to osteoarthritic degeneration (often as a result of prior lumbar fusion, a known risk factor(13)) or joint disruption associated with prior trauma. We excluded from analysis more rare causes of SIJ pain, such as tumour, ankylosing spondylitis, osteitis condensans ilii, Reiter's syndrome, psoriatic arthritis, or enteric arthritis. We also excluded patients with clearcut evidence of lumbar spine instability, hip osteoarthritis or other hip conditions.

In our neurosurgical clinic, we offer patients with confirmed SIJ pain invasive treatments, such as RF denervation and minimally invasive SIJ fusion. Unfortunately, available treatment options were limited by the type of insurance coverage each patient had. Many insurance providers refused to cover more invasive treatments if a patient had undergone previous back surgery; therefore, only a minority of patients could undergo these more invasive procedures.

The focus of our analysis was to examine differences in patient characteristics in patients who underwent invasive treatments (RF denervation or SIJ fusion) vs. those who underwent conservative treatment due to insurance coverage limitations. We compared continuous variables across treatment provided using analysis of variance (ANOVA). We compared ordinal or nominal variables using either Fisher's test or Wilcoxon's test. Statistical analysis was performed using both Excel (Microsoft Corporation, Redmond, WA, USA) and R.(14)

Ethics committee approval was not required for this study as all treatments and follow-up were considered routine clinical care and no protected health information of individual patients is reported. Patient consent was therefore not required. 


\section{Results}

Of the more than 475 patients seen in our clinic during the study period with suspected SI joint pain, 189 were diagnosed with SIJ pain that persisted despite 6 months of conservative treatment. These 189 patients are the focus of this study. In 103 patients, insurance coverage for aggressive treatments (RF denervation and/or SIJ fusion) was denied; these patients were forced to undergo continued conservative management (CM). 56 underwent SI denervation with radiofrequency ablation and 30 underwent SIJ fusion.

Mean back pain duration was 2.8 years; patients in the CM group had longer pain duration (3.3 years) compared to those in the RF (2.6 years) and SIJ fusion (1.5 years) groups (Figure 1, p <.0001, Table 1). $25 \%, 12.5 \%$ and $6.7 \%$ of patients in the CM, RF ablation and SIJ fusion groups had pain for $>5$ years prior to first SIJ block. Patients in the CM group were more likely to have a history of prior lumbar fusion $(40 \%)$ vs. those treated with SIJ denervation $(36 \%)$ or SIJ fusion $(17 \%, \mathrm{p}=.0596)$.

Patients in the CM group were also much more likely to have prior lumbar fusion within 2 years prior to first diagnostic SIJ block (25\% for CM vs. 5\% for RF group and $0 \%$ for SIJ fusion group, $\mathrm{p}<.001)$. Amongst those undergoing lumbar fusion prior to SIJ block, mean time from lumbar fusion to SIJ diagnosis was much shorter in the CM group (2.0 years) vs. the other groups (4.3 and 10.5 years for RF denervation and SIJ fusion groups, Figure 2, ANOVA p<.001).

Of CM subjects with a history of prior lumbar fusion, 26 (63\%) had undergone fusion within 2 years prior to first SIJ block. 19 of these $26(73 \%)$ stated that back pain did not improve after lumbar fusion (Table 2). After lumbar fusion, pain distribution showed the following changes: better in $4(15 \%)$, leg better but buttock unchanged in 4 (15\%), lumbar pain better but leg unchanged in $2(8 \%)$, lumbar better but leg worse in 1 
(4\%), no change in $11(42 \%)$ and worse in $4(15 \%)$. No patient reported improvement in buttocks pain after lumbar fusion. In 20 cases (77\%), pain improvement attributed to lumbar fusion was absent.

\section{Discussion}

Safe, effective and cost-effective treatment for any health condition relies critically on accurate diagnosis. No treatment aimed at a specific body structure will be effective if the underlying diagnosis is inaccurate. In a previous study using this cohort, we noted marked improvement in SIJ pain and disability after SIJ fusion, with little improvement after RF denervation or CM (Figure 3); opioid use decreased in the surgical group but increased in the non-surgical groups.(10)

During this study, we noted that patients in whom aggressive treatment was denied by insurance ( $54 \%$ of our cohort) showed typical patterns of health care that suggested misdiagnosis and, more importantly, potentially inappropriate treatment. Patients in whom aggressive treatment was denied had longer pain durations and a higher likelihood of prior lumbar fusion. They commonly had a history of visiting multiple spine specialists without a specific diagnosis. They reported that these specialists had not performed "hands on" physical examinations (i.e., physical examination manoeuvres that stress the SIJ, such as thigh thrust, Gaenslen's test, compression test, FABER test). Rather, they reported that the physicians' diagnostic activities focused primarily on radiographic (typically MRI) findings. The resultant "diagnostic confusion" likely explains delayed time to SIJ pain diagnosis, during which period these patients were far more likely to have other surgeries, especially lumbar fusion. Previous lumbar fusion was a common reason why insurance companies rejected coverage for more aggressive treatment aimed at the SIJ. 
More concerningly, nearly $2 / 3$ of patients in this group who had undergone prior lumbar fusion underwent the fusion procedure within 2 years prior to SIJ pain diagnosis. This raises two possibilities. SIJ pain could have developed within two years after lumbar fusion. Lumbar fusion is reported to increase the risk of adjacent segment degeneration of the SIJ,(15) and SIJ pain explains up to $40 \%$ of persistent low back pain after lumbar fusion.(13) The rate of adjacent segment degeneration of the SIJ after lumbar fusion is not clear; in the lumbar spine rates are relatively low (16.5\% at 5 years, (16) $22 \%$ at 10 years(17)).

Alternatively, SIJ pain could have been present at the time the lumbar fusion procedure was performed, either as sole cause of low back pain (i.e., reflecting misdiagnosis) or concomitant disease. Our data do not allow us to make this distinction. However, the fact that nearly $3 / 4$ of patients who underwent lumbar fusion within 2 years prior to SIJ pain diagnosis derived very little benefit from the lumbar fusion suggests that the original source of low back pain was misdiagnosed in many cases and was likely to be from the SIJ.

The experience of patients undergoing $\mathrm{CM}$ in our cohort was substantially worse than those undergoing SIJ fusion; the latter experienced marked reductions in SIJ pain and associated disability and a reduced usage of opioids as previously reported (Figure 3). The group undergoing SIJ fusion had lower SIJ pain duration and was less likely to have undergone prior lumbar fusion.

In the setting of two randomized trials supporting the safety and effectiveness of SIJ fusion vs. non-surgical treatment, $(8,9)$ and consistent with data from our cohort(10) as well as other prospective cohorts,(18) our findings strongly suggest the existence of a major problem in back pain diagnosis. First, our data strongly suggest that many spine surgeons are unaware of the SIJ as a potential cause of back pain. This is unfortunate 
since the SIJ may contribute to a substantial proportion (15-25\%) of cases of chronic low back pain. $(3,4)$ Second, it appears that many spine surgeons rely more on radiographic findings (MRI) over standard clinical examination for low back pain diagnosis. While no radiographic test (CT or MRI) has been shown to diagnose SIJ pain, the condition can be diagnosed based on historical signs, physical examination tests and confirmatory diagnostic SIJ block. A recent review suggests that clinical examination for SIJ pain is one of the more accurate tests for low back pain diagnosis.(12) Although the specificity of lumbar spine MRI is poor,(19) it seems to be the cornerstone of low back pain diagnosis, at least in Spain. Without proper clinical examination, many incidental lumbar spine radiologic findings with no relationship with the patient's complaints may be assumed to be causal, and a lumbar surgery may be recommended when another treatment (for example, SIJ fusion) would be more appropriate. Delivery of the wrong surgery has clear negative impact on patient health as well as overall healthcare costs. In our cohort, many patients were a surgical procedure (SIJ fusion) that might have been helpful because they had already undergone a procedure (lumbar fusion) that was not helpful, possibly because of misdiagnosis. Forced to undergo continued conservative management, many of these patients derived little long-term benefit and were more likely at last follow-up to be taking opioids.(10)

We acknowledge several limitations to the above conclusions. First, although our data suggest poor diagnostic algorithms prior to examination in our clinic, we could not directly assess the quality of prior diagnostic manoeuvres. Nonetheless, our patients commonly told us that previous surgeon visits did not involve "hands-on" clinical examination but rather interpretation of lumbar spine imaging only. Second, for those patients who had undergone lumbar fusion prior to SIJ pain diagnosis, we were unable to directly observe benefit derived from the procedure. However, nearly three quarters 
of patients undergoing recent ( 2 years) lumbar fusion recalled no significant benefit from the procedure. For several reasons, our analysis cannot estimate the proportion of patients undergoing lumbar fusion who are misdiagnosed; patients whose back pain improves markedly after lumbar fusion have no reason to be seen in our clinic. However, we find it quite remarkable to have evaluated a large number of patients with newly diagnosed SIJ pain who had undergone recent lumbar fusion that provided little benefit.

Taken together, our findings suggest substantial room for improvement in low back pain diagnosis. Patients with SIJ pain have characteristic historical findings (inability to sit on the affected side), and physical examination tests for SIJ pain are inexpensive and sufficiently accurate.(12) In the setting of high-quality clinical data supporting the safety and effectiveness of SIJ fusion, we believe surgeons should pursue knowledge and expertise for this diagnosis.

\section{Conclusions}

Ineffective recent lumbar fusion was common in patients with newly diagnosed SIJ pain, suggesting that lack of surgeon education regarding the SIJ may lead to misdiagnosis and inappropriate lumbar spine surgery.

\section{Tables}

Table 1. Baseline characteristics of SIJ pain patients.

Table 2. Responses to lumbar fusion in CM patients who had lumbar fusion within 2 years prior to first confirmatory SIJ block. Highlighted subjects had improvement in overall pain.

\section{Figures}


Figure 1. Duration of pain prior to diagnosis of SIJ dysfunction by treatments received.

Figure 2. Years between lumbar fusion and confirmatory SIJ block by treatment received.

Figure 3. Response to surgical and non-surgical treatments of SIJ pain (10). 


\section{Citations}

1. Painter CF. Excision of the os innominatum. Arthrodesis of the sacro-iliac synchrondrosis. Boston Med Surg J. 1908;159(7):205-8.

2. Mixter W, Barr J. Rupture of the intervertebral disc with involvement of the spinal canal. NEJM. 1934;211(5):210-5.

3. Sembrano JN, Polly DW. How often is low back pain not coming from the back? Spine. 2009 Jan 1;34(1):E27-32.

4. Bernard TN, Kirkaldy-Willis WH. Recognizing specific characteristics of nonspecific low back pain. Clin Orthop Relat Res. 1987 Apr;(217):266-80.

5. Cher D, Polly D, Berven S. Sacroiliac joint pain: burden of disease. Med Devices (Auckl). 2014;7:73-81.

6. Ackerman SJ, Polly DW Jr, Knight T, Holt T, Cummings J Jr. Nonoperative care to manage sacroiliac joint disruption and degenerative sacroiliitis: high costs and medical resource utilization in the United States Medicare population. J Neurosurg Spine. 2014 Feb 14;20(4):354-63.

7. Ackerman S, Polly DW, Holt T, Cummings JT, Knight T. Management of sacroiliac joint disruption and degenerative sacroiliitis with nonoperative care is medical resource-intensive and costly in a United States commercial payer population. Clinicoecon Outcomes Res. 2014 Feb 11;2014(6):63-74.

8. Polly DW, Swofford J, Whang PG, Frank C, Glaser JC, Limoni RP, et al. TwoYear Outcomes from a Randomized Controlled Trial of Minimally Invasive Sacroiliac Joint Fusion vs. Non-Surgical Management for Sacroiliac Joint Dysfunction. Int J Spine Surg. 2016 Aug 23;10:Article 28.

9. Dengler J, Kools D, Pflugmacher R, Gasbarrini A, Gaetani P, Cher D, et al. 1-Year Results of a Randomized Controlled Trial of Conservative Management vs. Minimally Invasive Surgical Treatment for Sacroiliac Joint Pain. Pain Physician. 2017;20:537-50.

10. Vanaclocha V, Herrera JM, Sáiz-Sapena N, Rivera-Paz M, Verdú-López F. Minimally Invasive Sacroiliac Joint Fusion, Radiofrequency Denervation, and Conservative Management for Sacroiliac Joint Pain: 6-Year Comparative Case Series. Neurosurgery. 2018 Apr 20;82(1):48-55.

11. Fortin JD, Falco FJ. The Fortin finger test: an indicator of sacroiliac pain. Am J Orthop. 1997 Jul;26(7):477-80.

12. Petersen T, Laslett M, Juhl C. Clinical classification in low back pain: bestevidence diagnostic rules based on systematic reviews. BMC Musculoskelet Disord. 2017 May 12;18(1):188.

13. DePalma MJ, Ketchum JM, Saullo TR. Etiology of Chronic Low Back Pain in Patients Having Undergone Lumbar Fusion. Pain Med. 2011 Apr 11;12(5):732-9. 
14. R Core Team (2013). R: A language and environment for statistical computing. [Internet]. Vienna, Austria; Available from: http://www.R-project.org/

15. Ha K-Y, Lee J-S, Kim K-W. Degeneration of sacroiliac joint after instrumented lumbar or lumbosacral fusion: a prospective cohort study over five-year follow-up. Spine. 2008 May 15;33(11):1192-8.

16. Ghiselli G, Wang JC, Bhatia NN, Hsu WK, Dawson EG. Adjacent segment degeneration in the lumbar spine. J Bone Joint Surg Am. 2004 Jul;86-A(7):1497503.

17. Sears WR, Sergides IG, Kazemi N, Smith M, White GJ, Osburg B. Incidence and prevalence of surgery at segments adjacent to a previous posterior lumbar arthrodesis. Spine J. 2011 Jan;11(1):11-20.

18. Duhon BS, Bitan F, Lockstadt H, Kovalsky D, Cher D, Hillen T. Triangular Titanium Implants for Minimally Invasive Sacroiliac Joint Fusion: 2-Year FollowUp from a Prospective Multicenter Trial. Int J Spine Surg. 2016;10:Article 13.

19. Boden SD, Davis DO, Dina TS, Patronas NJ, Wiesel SW. Abnormal magneticresonance scans of the lumbar spine in asymptomatic subjects. A prospective investigation. J Bone Joint Surg Am. 1990 Mar;72(3):403-8. 


\section{Table Captions}

Table 1. Baseline characteristics of SIJ pain patients.

\begin{tabular}{|l|r|r|r|r|}
\hline Characteristic & $\begin{array}{c}\text { CM Only } \\
(\mathbf{n}=\mathbf{1 0 3})\end{array}$ & $\begin{array}{r}\text { SI Denervation } \\
\text { (n=56) }\end{array}$ & $\begin{array}{c}\text { SIJ Fusion } \\
(\mathbf{n}=\mathbf{3 0})\end{array}$ & P value* \\
\hline Age, mean (SD) & $52.0(10.5)$ & \multicolumn{1}{|c|}{$48.8(12.5)$} & $28.8(12.0)$ & .155 \\
\hline N, \% female & $65(63.1 \%)$ & $30(53.6 \%)$ & $18(60 \%)$ & .5034 \\
\hline Body mass index, mean (SD) & $27.5(4.6)$ & $29.1(4.8)$ & $29.2(5.2)$ & .0568 \\
\hline Smoker, N (\%) & $43(41.7 \%)$ & $19(33.9 \%)$ & $13(43.3 \%)$ & .5697 \\
\hline \% bilateral SIJ pain & $26(25.2 \%)$ & $11(19.6 \%)$ & $11(36.7 \%)$ & .2241 \\
\hline SIJ pain duration (years), mean (SD) & $3.3(2.5)$ & $2.6(2.5)$ & $1.5(1.7)$ & .0017 \\
0-1 years & $21(20.4 \%)$ & $21(37.5 \%)$ & $22(73.3 \%)$ & \\
1-5 years & $55(53.4 \%)$ & $28(50.0 \%)$ & $6(20 \%)$ & \\
>5 years & $26(25.2 \%)$ & $7(12.5 \%)$ & $2(6.7 \%)$ & \\
Unknown & $1(1 \%)$ & $0(0.0 \%)$ & $0(0 \%)$ & \\
\hline Activities that worsen pain & & & & \\
General activity & $33(32 \%)$ & $8(14.3 \%)$ & $10(33.3 \%)$ & .0381 \\
Driving & $42(40.8 \%)$ & $42(75.0 \%)$ & $26(86.7 \%)$ & $<.0001$ \\
Lying in bed & $45(43.7 \%)$ & $19(33.9 \%)$ & $5(16.7 \%)$ & .0230 \\
Sitting & $86(83.5 \%)$ & $44(78.6 \%)$ & $30(100 \%)$ & .0281 \\
Standing & $96(93.2 \%)$ & $43(76.8 \%)$ & $26(86.7 \%)$ & .0121 \\
Walking & $5(4.9 \%)$ & $5(8.9 \%)$ & $1(3.3 \%)$ & .4722 \\
\hline Car accident & & & & \\
Fall & $2(1.9 \%)$ & $2(3.6 \%)$ & $0(0.0 \%)$ & .5390 \\
Lumbar fusion & $16(15.5 \%)$ & $14(25.0 \%)$ & $7(23.3 \%)$ & .3036 \\
Pregnancy & $36(35.0 \%)$ & $17(30.4 \%)$ & $3(10 \%)$ & .0309 \\
Spontaneous & $2(1.9 \%)$ & $1(1.8 \%)$ & $0(0 \%)$ & .7480 \\
Primary underlying cause & $47(45.6 \%)$ & $22(39.3 \%)$ & $20(66.7 \%)$ & .0480 \\
Lumbar fusion & $41(39.8 \%)$ & $20(35.7 \%)$ & $5(16.7 \%)$ & .0596 \\
Lumbar discectomy & $3(2.9 \%)$ & $0(0 \%)$ & $0(0 \%)$ & .7344 \\
Hip replacement & $1(1.0 \%)$ & $1(1.8 \%)$ & $1(3.3 \%)$ & .5747 \\
\hline Prior surgeries & & &
\end{tabular}




\begin{tabular}{|c|c|c|c|c|c|}
\hline ID & Age & Sex & $\begin{array}{l}\text { Did pain improve } \\
\text { after lumbar fusion? }\end{array}$ & $\begin{array}{c}\text { Did pain distribution } \\
\text { change after lumbar fusion? }\end{array}$ & $\begin{array}{l}\text { Do you think your pain improvement was } \\
\text { related to lumbar fusion? }\end{array}$ \\
\hline 105 & 30 & Female & Minimal improvement & Lumbar pain somewhat improved, buttock + leg pain unchanged & Not related \\
\hline 32 & 62 & Male & No change & Worse pain & Not related \\
\hline 112 & 40 & Male & No improvement & Worse pain than before same distribution & Not related \\
\hline 33 & 47 & Male & No improvement & The same pain & Lumbar fusion useless \\
\hline 38 & 54 & Male & No improvement & Worse pain & Not related with the lumbar fusion \\
\hline 42 & 49 & Female & No improvement & The same pain, no change & Not related \\
\hline 49 & 52 & Female & No improvement & Just the same pain as before if not worse & Lumbar fusion useless \\
\hline 69 & 48 & Male & No improvement & Pain as before & Lumbar fusion not useful \\
\hline 111 & 61 & Male & No improvement & No, worse pain & Not related \\
\hline 57 & 46 & Female & No improvement & Same pain & Not related \\
\hline 64 & 57 & Male & No improvement & Changed the leg pain but not the buttock pain & Not related \\
\hline 84 & 41 & Male & No improvement & Same pain & Not related with the lumbar fusion \\
\hline 95 & 71 & Female & No improvement & Same pain & Not related \\
\hline 114 & 66 & Female & No improvement & Pain as before & Lumbar fusion useless \\
\hline 117 & 45 & Male & No improvement & Less leg pain but more buttock pain & Not related \\
\hline 56 & 56 & Female & No improvement, worse pain & No improvement, worse pain every day & No related \\
\hline 51 & 58 & Male & No, little improvement & Moderate change & Same pain, not related with the lumbar fusion \\
\hline 35 & 49 & Female & Pain improvement for 1 month & The same pain & Improvement after removal of lumbar arthrodesis \\
\hline 52 & 34 & Male & $\begin{array}{l}\text { Initial improvement particularly leg pain, } \\
\text { worse lumbar pain since } 2013\end{array}$ & Yes, no more leg and lumbar pain but lumbar pain recurred 2013 & $\begin{array}{l}\text { Yes, very much related, but new pain appeared five } \\
\text { years later }\end{array}$ \\
\hline 101 & 55 & Female & Moderate improvement & Same pain & Not related \\
\hline 80 & 59 & Female & Some improvement but not much & Less lumbar pain but some buttock and leg pain & Moderate improvement \\
\hline 45 & 29 & Male & $\begin{array}{l}\text { Yes but slow improvement }+ \text { persistent } \\
\text { buttock pain }\end{array}$ & Sciatica gone but persistent buttock pain & $\begin{array}{l}\text { Yes, related with the lumbar pain but not with the } \\
\text { buttock pain }\end{array}$ \\
\hline 31 & 50 & Female & Yes, for 4 months then pain again & Yes, no mora sciatica but more buttock persistent pain & Different pain \\
\hline 55 & 58 & Male & Yes, great improvement & Pain much improved & Related with the lumbar fusion \\
\hline 67 & 70 & Male & Yes, improvement & Improvement & Yes, related with the lumbar fusion \\
\hline
\end{tabular}




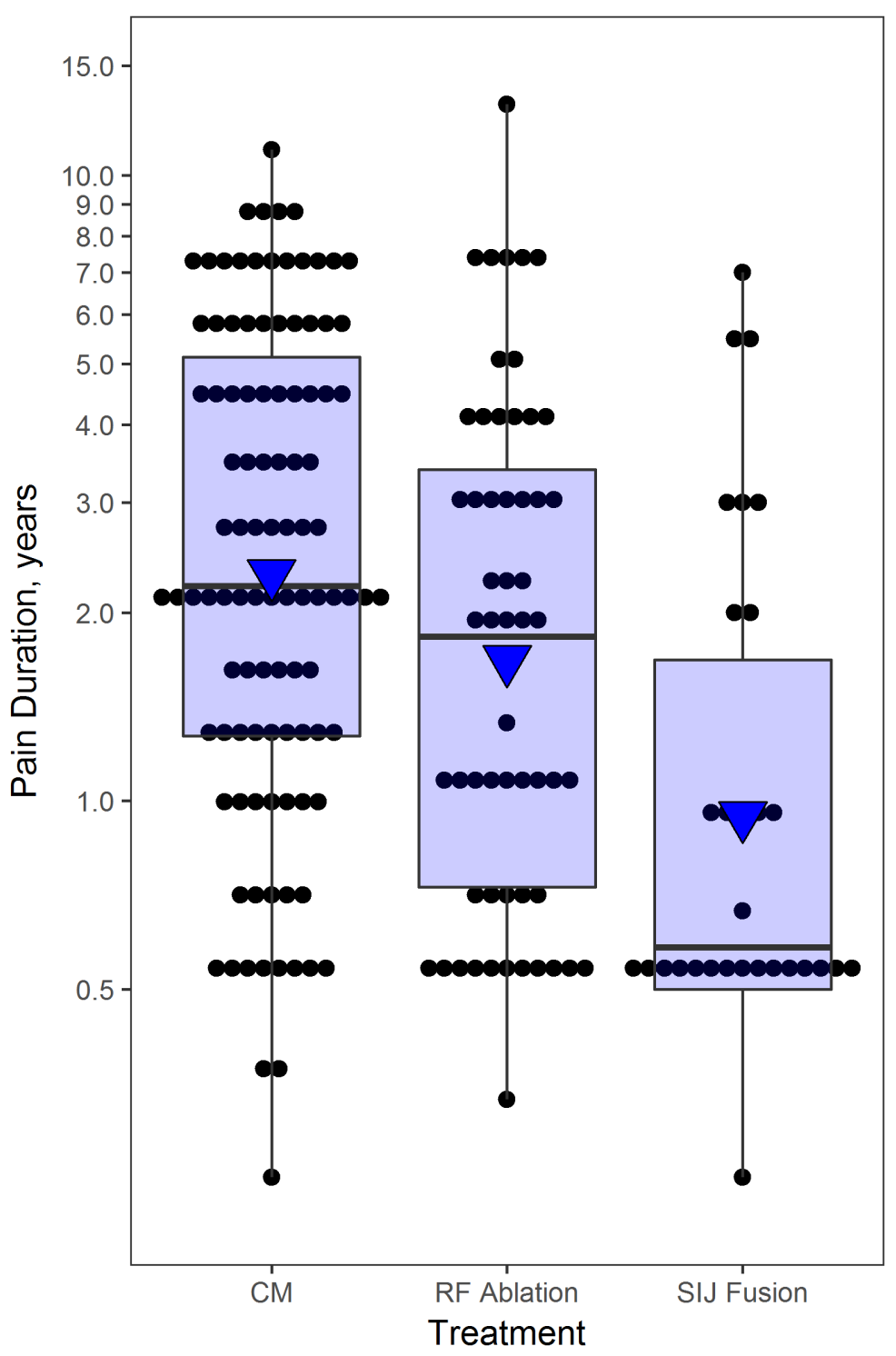


VAS SIJ pain

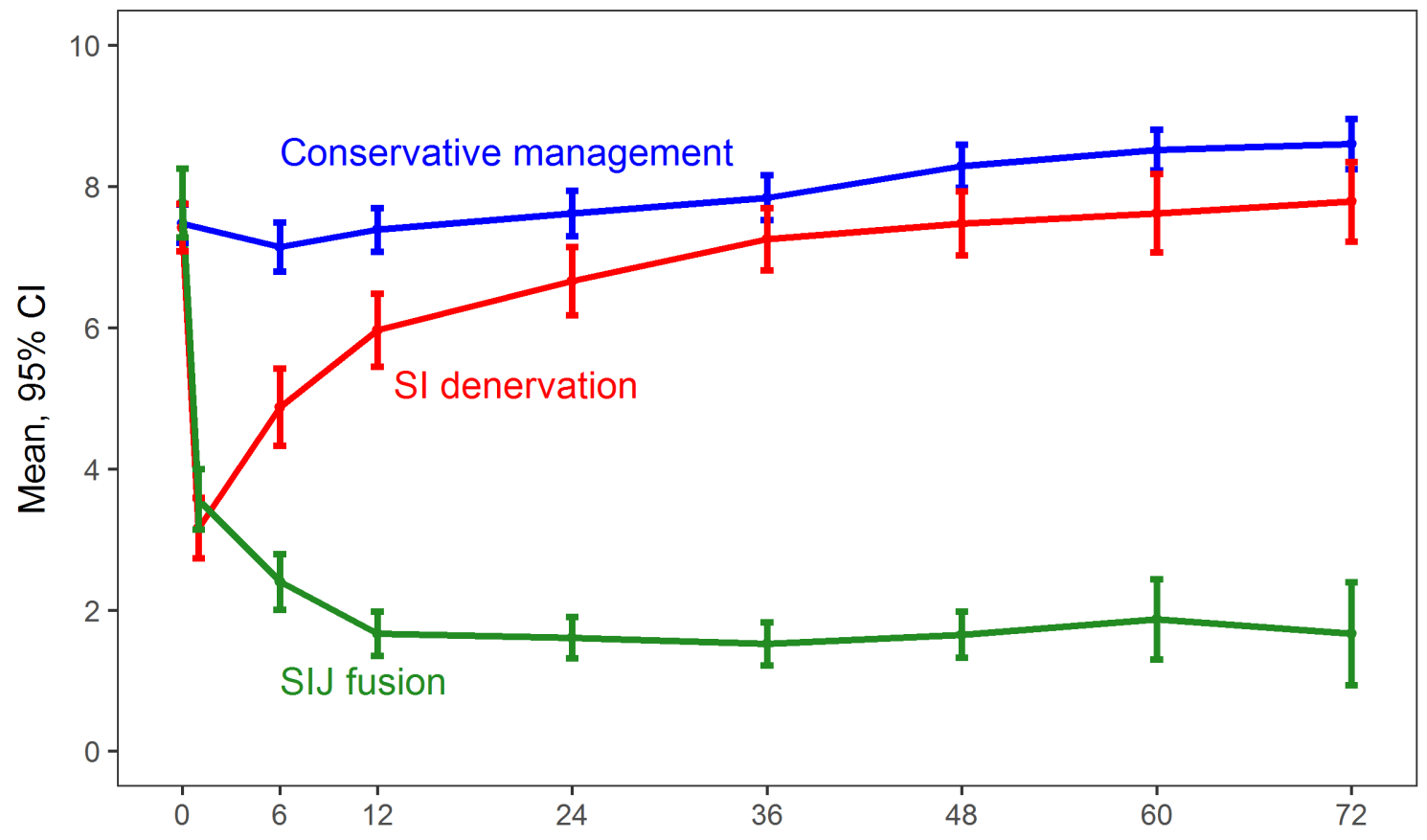

Oswestry Disability Index

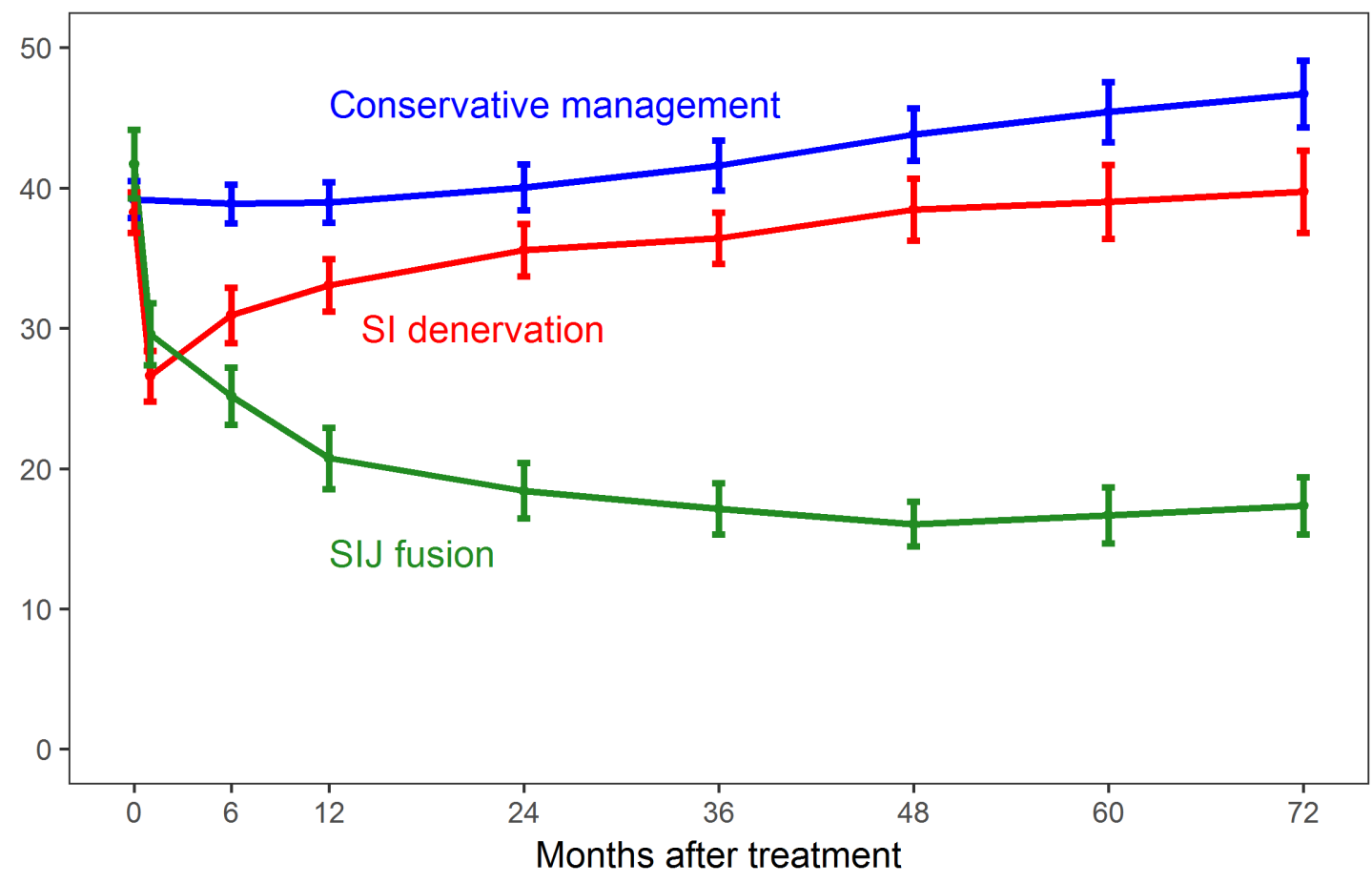

